\title{
Corpo, masculinidade e efeminização: uma análise da produção dos sujeitos homossexuais on-line
}

Body, masculinity and feminization: an analysis of homossexual subjects online

\section{Atilio Butturi Junior}

Universidade Federal da Fronteira Sul, campus Erechim, RS, Brasil

Resumo: Este artigo parte das discussões sobre sujeito e liberdade presentes na arqueogenealogia foucaultiana e tem por objetivo analisar a produção dos sujeitos homossexuais nos discursos virtuais. Para tanto, o corpus utilizado é composto de discursos que circulam em dois grandes sites brasileiros, o Disponível.com e o Bate Papo UOL. As análises permitem observar um funcionamento discursivo pautado na diferenciação entre práticas masculinas positivas e práticas efeminadas negativas. Conclui-se, a partir de então, que o dispositivo sexual brasileiro está ainda marcado por um discurso fantasma, cindido entre uma assunção pública da diversidade e uma negação de seu aparecimento na esfera privada.

Palavras-chave: Discurso homossexual. Sujeito. Resistência. Discurso virtual.

Abstract: This article starts from the discussions on subject and freedom present in foucaultian archaeogenealogy, and its objective is to analyze the production of homosexual subject in virtual discourses. For this, the corpus used consists of discourses circulating in two large Brazilian sites, Disponivel.com and Bate Papo UOL. The analyses allow observing a discursive functioning guided by the differentiation between positive male practices and negative effeminate practices. From this, it is concluded that the Brazilian sexual vision is still marked by a shadow reasoning, split between a public assumption of diversity and a denial of its appearance in the private sphere.

Keywords: Homosexual discourse. Subject. Resistance. Virtual discourse. 


\section{Introdução}

Seguindo Facchini (2003), no Brasil, a partir da década de 90 do século $\mathrm{XX}$, inicia-se um processo de visibilidade e orgulho gay. Sob a égide inicial do GLS (sigla para gays, lésbicas e simpatizantes forjada na década de 90), surgem algumas séries de enunciados: enunciados de "orgulho" e de assunção de identidade, calcados em estratégias de coming-out; enunciados da virilidade corporal, que tornam a homocorporalidade uma espécie de função distintiva; enunciados sobre a "modernidade" dos comportamentos - no Brasil, como o caso dos clubbers e das

Atilio drag-queens; enunciados de defesa e luta pelos direitos civis - "casamenButturi Junior to", homoparentalidade etc.

De acordo com a mesma autora (FACCHINI, 2003), o discurso GLS aparece no Brasil na coluna de André Fisher, na Folha de São Paulo, em meados da década de 90. Fisher é o mesmo que, em 1993, realizou o Festival Mix Brasil da Diversidade Sexual e o primeiro Mercado Mundo Mix. Até hoje, é o responsável pelo primeiro site GLS do Brasil, o MixBrasil.

Tendo em vista essa nova discursividade positivante, este artigo tem por objetivo analisar, de uma perspectiva arqueogenealógica (Foucault), a emergência de um discurso da/sobre a homossexualidade que, a partir da década de 90, caracteriza as relações homoeróticas e homocorporais na internet. Para isso, o recorte do corpus parte de dois dos sites mais acessados para práticas afetivas e sexuais entre os homossexuais masculinos no Brasil, quais sejam: o Disponível.com e o Bate Papo UOL, com dados coletados entre setembro de dezembro de 2011. A hipótese defendida aqui é a de que há, no discurso de subjetivação e objetivação das homossexualidades brasileiras on-line, uma espécie de cisão axiológica entre práticas masculinas e efeminadas, sendo as primeiras da ordem do verdadeiro e do positivo e as segundas tomadas como abjetas ou fora da norma.

A fim de forjar a análise, o texto se divide em algumas seções: na primeira, recorre-se a Foucault para inteligir a relação entre poder e resistência dos sujeitos no dispositivo sexual; na segunda, apontam-se características do virtual; na terceira e na quarta, realizam-se as análises dos sites. Finalmente, as considerações finais retomam a hipótese da cisão e da hierarquia, atestada nas análises. 


\section{Sujeito, ética e moral}

Foucault (2010b) aponta, em sua problematização do sujeito, duas possibilidades: primeiramente, a partir de práticas coercitivas; mais tarde, segundo o imperativo das práticas de si. o deslocamento entre os dois casos, no interior de sua "genealogia", residiria na relação urdida com os jogos da verdade: enquanto a análise dos sistemas de objetificação Vigiar e punir e A vontade de saber - exigia uma teoria da sujeição, a análise do que chama da governamentalidade (dos outros e de si) oferece à genealogia uma teorização das estratégias de resistência e de liberdade por meio das formas de subjetivação.

De acordo com Weinmann (2006), que entabula um diálogo entre liberdade, sujeito e dispositivo, haveria, na genealogia foucaultiana, um adensamento da constitutividade entre liberdade e poder, já que o

Corpo, masculinidade e efeminização filósofo francês assume uma incitação recíproca de poder e resistência, legando à subjetividade um papel tático de modificações microfísicas no interior dos dispositivos e dos diagramas. Essa tensão de nunca acabar descreve uma agonística na produção da subjetivação, descrita por Foucault em sua genealogia, na qual, inicialmente, a constituição da subjetividade pode ser lida como criação da "alma" no interior do corpo, por meio da docilização, e parte do advento das tecnologias disciplinares e das ditas Ciências do Homem (FOUCAULT, 1993d). A hipótese do autor é de que teria havido três tipos de tecnologia política: a do suplício, ligada ao poder do soberano; a da punição, cuja pretensão inicial é a reformista; e a disciplinar, fundamentada num poder sobre o corpo produtor de interioridade e sobre uma física do espaço e do tempo. Essa última configuração do poder é justamente a capaz de produzir a alma no corpo como um efeito do poder.

Essa genealogia tem por característica a "insurreição dos saberes dominados" (FOUCAULT, 1993a, p. 170) na tentativa de deslindar tudo o quanto foi expulso como resíduo na construção dos discursos da cientificidade conforme os conhecemos. Trata-se, pois, de interrogar a positividade dos saberes a sua exterioridade, sua relação necessária e direta com estratégias micro e macrofísicas pelas quais o poder é exercido. No caso do sujeito, a empresa é inquirir sobre as tecnologias de produção do si-mesmo através do corpo, historicizando a produção da alma moderna (FOUCAULT, 1993d).

Dessa perspectiva, em Vigiar e punir, Foucault teoriza sobre um poder do tipo onipresente e construtivista que só existe em ação e que 
seu locus privilegiado (desde o século XVIII) é o corpo. Segundo Ewald (2000), o próprio do poder disciplinar é ter a forma de um "corpo a corpo". De um lado, o "corpo político", com suas instituições e maquinarias; do outro, a submissão dos corpos e seu investimento subjetivante. É por essa razão que a genealogia é uma "anatomia política": física dos corpos, porque realizada conforme um campo de visão, de divisão e de enunciação; economia do poder nos corpos, porque os investe de “alma" através de "ínfimas materialidades" (EWALD, 2000, p. 45).

A novidade e a distensão foucaultianas estariam, segundo Ewald

Atilio Butturi Junior (2000), na relação da ordem microfísica corporal que o autor de Vigiar e punir estabelece, levando em conta procedimentos e discursos de sujeição do corpo (produzindo ordem e "docilidade"), de investimento do corpo (produzindo a alma moderna) e de objectivação do corpo (produzindo discursos e maquinarias sobre o sujeito).

Todavia, a hipótese de uma sujeição total é colocada em xeque já no texto sobre a prisão, quando Foucault (1993d) considera, por exemplo, que há resistência e perigo mesmo quando se exerce o poder do soberano, justamente porque sua publicidade, violência e transparência seriam capazes de, a qualquer momento, transformar os afetos da multidão diante da maquinaria régia. Em O uso dos prazeres (2009b), Foucault passará a averiguar justamente aquilo que engendra as resistências, a saber, as relações que os sujeitos travam com a verdade e o poder.

A inflexão de Foucault não é um abandono: permanece-se discutindo as formas de invenção recente, tarefa de As palavras e as coisas, mas impõe-se que se reflita sobre uma autoconstituição seguindo o modelo da resistência. Segundo Deleuze (2005, p. 109), a novidade de $O$ uso dos prazeres e da problematização das práticas de si e da subjetivação seria o aparecimento de "uma dimensão da subjetividade que deriva do poder e do saber, mas que não depende deles".

No entanto, o aparecimento da instância subjetiva é também bipartido. Haveria uma necessária ligação entre sujeito e moral cujo imperativo seria o de se distinguir entre dois "modelos" de intersecção entre código e formas de subjetivação. De um lado, supõe-se a existência de morais sistemáticas, capazes de subsumir todas as formas de comportamento, em que a subjetivação opera com pouca liberdade - dir-se-ia, com menos resistência. Em Foucault, a reflexão da genealogia acaba por açambarcar tanto o domínio das histórias da moral quanto o domínio das histórias da ética e da constituição dos sujeitos. Se havia uma constituição 
entre poder e resistência, justamente porque o primeiro criava campos de positividades discursivas a que devia dominar e a que a ele deveria resistir, o posicionamento adotado desde então é o de que existem deslocamentos subjetivos, dobras do lado de dentro (DELEUZE, 2005), adequadas ao caráter "transversal" dos dispositivos e dos diagramas.

Segundo a tese dos deslocamentos subjetivos, porém, ressalte-se que, no mesmo 0 uso dos prazeres (FOUCAULT, 2009b), Foucault aponta uma modificação importante com o advento do Cristianismo. Para ele, ainda que não fosse a cristandade a responsável pela "legalização" das práticas de si com ênfase na codificação moral, visto que também na Antiguidade já haveria uma preocupação ética, estética e "ascética" no governo de si (e dos outros), o Cristianismo ofereceu uma "articulação entre a lei e o desejo" bastante peculiar, que se marcava pela codificação em detrimento da ética subjetivante.

Além da modificação cristã rumo à moral codificada, sabe-se que também as Ciências do Homem, amplamente cartografadas em suas "baixas origens", foram alvo de uma descrição: em Vigiar e punir, com a produção da delinquência pelos discursos médico-legais e maquinarias do poder; na Vontade de saber, com a hipótese do dispositivo da sexualidade agenciando os sujeitos a partir do desejo.

Depois desse adensamento "moral", também é mister tomar em consideração o delicado "tema" da resistência. Como foi afirmado anteriormente, a genealogia aposta da dobradura subjetiva, "irredutível aos saberes e poderes dos quais deriva" (WEINMANN, 2006, p. 21). Todavia, se há um movimento incessante de pressão subjetiva e resistência, existe também uma nova recodificação, visto que os dispositivos e diagramas são, por excelência, atravessados pelo falhamento e prenhes de transformação. Assim, conforme Weinmann (2006, p. 21), “esse novo domínio - o si próprio - é continuamente penetrado, recuperado e reintegrado em novos saberes e poderes, que o recodificam e o rediagramatizam, de modo a assujeitar (ao outro: submissão; a si próprio: identidade) a subjetivação".

Do pensamento de Weinmann, destaco o termo "reintegrado" porque não se trata de um poder do tipo soberano, a função-poder a que recorre Foucault não permite nem uma escatologia de liberdade marxiana nem uma dominação absoluta. No entanto, prevê que poder e resistência, diagrama e sujeito do diagrama, travam lutas microfísicas. Nesse caso, postularíamos uma gramática de variáveis inversamente 
proporcionais. Dito de outro modo: ainda que a resistência exija novas formas de poder/saber, outras maquinarias e uma metamorfose nos discursos, o dispositivo e o diagrama são capazes também de recriação. Gostaria de destacar, neste trabalho, justamente a capacidade de recriação desse dispositivo a partir das resistências, normatizando e disciplinarizando os sujeitos de novas formas e segundo outros objetivos.

Volto, então, ao dispositivo da sexualidade. No caso do sexo, para Foucault, esse poder é exercido a partir do século XVII, em dois níveis: o corpo individual, na positividade da criação de modos disciplinarizados Atilio de vivenciar prazer; e o corpo social, como tecnologia da população e Butturi Junior do combate à degenerescência. A conjunção de tecnologias do corpo e da população Foucault (2009a) chamou de biopoder, encarnado no dispositivo da sexualidade. Como dispositivo, a sexualidade é necessariamente demarcada por Foucault (1993c, p. 244) a partir de três características: é uma rede que engloba tanto discursos como instituições, leis, enunciados científicos, leigos e afins; entre a heterogeneidade desses elementos englobados, há um jogo específico e móvel de posições e funções; todo esse dispositivo responde a uma urgência histórica, tem "uma função estratégica dominante".

A lógica do dispositivo operaria em duas ordens complementares: a ordem jurídico-estatal da lei, encarnada na instituição e no aparelhamento; e a ordem da regulação normativa, encarnada na capacidade positiva - e impositiva - que tem o poder de fomentar no indivíduo (corpo) e no social (população) entendimentos de si - estratégicos e éticos ou morais.

Em A vontade de saber (FOUCAULT, 2009a), há uma lista de quatro regras, "prescrições de prudência" para se descrever a sexualidade no dispositivo: regra da imanência, pois a sexualidade nunca é objetiva, mas um investimento entre "técnicas de saber e estratégias de poder" (p. 109); regra da variação contínua, pois a sexualidade é regida por modificações e cortes nas correlações que fazem seu jogo; regra do duplo condicionamento, porque há uma tensão constitutiva entre o condicionamento do poder global e o dos encadeamentos locais; regra da polivalência tática dos discursos, visto que eles podem servir tanto para veicular quanto para minar o poder.

Então, vejamos: o dispositivo aqui absorve a transformação como característica. Ademais, um entendimento mais normatizador respeita a variação contínua do jogo e a polivalência tática, justamente porque 
intenta - tal será a tarefa da análise - descrever como discursos de resistência sobre a homossexualidade masculina brasileira acabaram absorvidos como discursos da norma e da docilização dos corpos e dos sujeitos. Uma docilização com tintas ubuescas.

Acredita-se, pois, que há uma ênfase na moralidade e na assunção de subjetividades socialmente marcadas como identidades, em detrimento do criacionismo e da invenção. Como já foi afirmado, o recorte aqui não pretende a exaustividade das práticas, assumindo que, ao menos foucaultianamente, possibilidades de resistência existem. Entretanto, marcada a importância na própria genealogia dos movimentos de estratificação, cabe inventariar os códigos que sustentam a homossexualidade sob a égide da passividade.

Para este trabalho, cabe ainda questionar como essa permanên-

Corpo, masculinidade e efeminização cia e essa força performativa atuam nos discursos de resistência. Isso implica aduzir nos discursos de valorização positiva da identidade homossexual no Brasil a marca ubuesca da negação das práticas passivas como resquício engendrado no interior de práticas de moralidade e, nessa esteira, colocar em xeque seu poder subversivo, da ordem da ética e das formas de subjetivação. É, pois, sobre esse dispositivo materializado nos discursos sexuais e virtuais seus que trataremos nas seções a seguir.

\section{O discurso do virtual}

Ao tomar os discursos on-line como objeto, faço uma ressalva, seguindo Lévy (1999): as mudanças na tecnologia têm um impacto na produção dos discursos e, no caso de uma "cibercultura", é preciso atentar para a função de deslocamento que os sujeitos possuem, em termos de interatividade. Não quero, com isso, nem reafirmar o "otimismo" de Lévy de um mundo mais democrático nem imaginar uma esfera de liberdades irrestritas. Para a discussão aqui proposta, entretanto, vale a pena assumir um deslocamento dos enunciados relativo ao virtual segundo a modificação da materialidade enunciativa.

Dito de outra forma, quero, com Maingueneau (2002), postular que a materialidade e o discurso são constitutivos e que, na contemporaneidade, divisões entre a oralidade e a escrita, o formal e o informal, devem ser colocadas em suspenso. Quanto aos enunciados que circulam na internet e sobre os quais me debruço agora, é essa mudança que se revela fundamental, pois nota-se um deslocamento dos discursos, que supostamente circulam em esferas públicas e formais, para uma 
materialização menos formal e mais privativa. Com isso, quero asseverar que, nos sites pesquisados, as escritas de si dos sujeitos homossexuais, apesar de publicizadas ao extremo, guardam traços de esferas menos institucionalizadas. Por conseguinte, são capazes de indicar pontos nevrálgicos diante da configuração discursiva a que "pertencem", trazendo à tona um problemático silenciamento da efeminização e da passividade, como discursos fantasmáticos da ordem monossexual que constituem.

No que se refere aos discursos sobre/da homossexualidade, sa-

Atilio Butturi Junior be-se que o primeiro site brasileiro de grande alcance na discussão e na produção da homossexualidade é o MixBrasil, que parte de uma série de posicionamentos no campo enunciativo que o tornaram uma "referência" na constituição virtual de um discurso GLS. Essa universalização e essa produção, porém, serão reformuladas em termos de diversidade: no discurso da privacidade que se constitui na internet, o que se notará é um recrudescimento dos discursos de identificação masculina única e, nessa esteira, de produção e expulsão das alteridades.

Para Heilborn (2009, p. 85), pode ser observada uma mudança em relação à hierarquia, entre os sujeitos da década de 80 e aqueles entrevistados pela autora no século XXI: "entre as gerações mais jovens, a preocupação com uma assimetria de gênero não desponta no discurso. Essa ausência pode ser debitada à ausência de uma argumentação que aluda ao ideário feminista." A autora sugere que, diferentemente do que ocorria na geração do desbunde, a vanguarda sexual, a diversidade e a igualdade não são enunciados que percorrem as falas dos sujeitos mais jovens, quando estes respondem sobre papéis sexuais e sociais. Essa despreocupação hierárquica deve ser aduzida como uma série nova de discursos, que vai se contrapor à igualdade alardeada pelo desbunde e, de alguma forma, acabar pondo em xeque as identidades "múltiplas" GLS, na medida em que permite entrever práticas afetivas e sexuais que retomam o modelo hierárquico, muitas vezes tido como esgotado.

Além disso, é preciso que as análises aqui realizadas sejam lidas segundo uma preocupação com as regras do dispositivo e, portanto, seguindo uma disciplina de verdadeiro. Com isso, sugiro que, não obstante uma interpretação performática das encenações de gênero e de sexualidade que encerram os enunciados e as identidades dos sujeitos do corpus, o ponto nodal desta pesquisa reside em pensar as relações que os sujeitos detêm com a verdade de seu desejo. Dessa perspectiva, 
parte-se do pressuposto de que, na esfera da privacidade on-line, além de performarem, os sujeitos se implicam naquilo que produzem como suas subjetividades. É da perspectiva de uma vontade de verdade no dispositivo que esta seção se justifica.

Vou aos corpos e ao corpus. São duas fontes desses discursos que utilizo para a análise: o Disponível.com e as páginas de seus usuários, e as salas do Bate Papo UOL, destinadas ao sexo entre homens - salas de sexo gay, na classificação do provedor. Como se trata de averiguar os pontos de contato entre os enunciados que circulam nessas duas esferas, metodologicamente opto por descrevê-las numa só seção. A pesquisa não se preocupou com a extensão dos dados nem se pensou exaustiva: meu objetivo era menos uma descrição minuciosa de todos os discursos que circulam nas páginas da rede e mais um esforço de atenção para os

Corpo, masculinidade e efeminização enunciados que estão em constante reescrita e negociação. Um objetivo funcionalmente interpretativo.

\section{O disponível e a construção do "ativo"}

Primeiramente, a abordagem é do Disponível.com. $\mathrm{O}$ site de relacionamentos entre homens assim se define:

O Disponivel.com está no mercado desde 2003 e se consolidou como o maior site de relacionamento gay do país e isso se dá também pelo respeito e a seriedade que a privacidade do usuário é tratada, conferindo assim a segurança de que nenhum dado será informado a terceiros. (DISPONÍVEL.COM, 2011).

Como se trata de um discurso a ser cuidadosamente mantido em sigilo, o que se torna paradoxal no caso de um site de exposição de si, a organização gráfica do site é econômica: apenas um espaço para login inicial, para cadastramento de novos usuários e poucos links de acesso, sobretudo em caso de problemas com as "contas". Sem me deter numa ampla discussão sobre a homocorporalidade, é preciso de antemão atentar para o jogo discursivo que se instaura a partir da tela inicial do Disponível.com. As imagens são claras na construção de uma masculinidade específica, segundo os padrões de uma virilidade, dir-se-ia, hipersaudável. Nessa produção, lê-se "Os homens mais bonitos disponíveis pra você!" Não há, aqui, nenhum resquício de uma gramática da diversidade: homens, como se verá, vai sofrer uma espécie de saturação 
de masculino, similar ao que Perlongher (1987) considerava o "travestismo" dos "michês": um simulacro e um exagero das virtudes do masculino inscritas no dispositivo sexual. No Disponível.com, trata-se de encenar uma dramática desse macho-homossexual, como se verá.

É mister, também, contemplar sua configuração formal. Quanto ao funcionamento, o site é simples: uma rede social em que os usuários trocam informações, imagens e contatos, majoritariamente com objetivos sexuais. Para ter acesso aos perfis dos usuários, é necessária a criação de uma "conta" e a ativação de um perfil. No caso deste traba-

Atilio Butturi Junior lho, foi criado o perfil Pesquisador 4, em outubro de 2011.

Para investigar o discurso das homossexualidades no site, vali-me da classificação que se realiza entre os perfis, dando conta das preferências dos usuários. No Disponível.com, essas preferências estão organizadas na forma de listas regionais que ranqueiam os perfis mais visitados e os perfis mais adotados como favoritos. No universo do ranqueamento, optei por observar os perfis "mais visitados" de seis estados: São Paulo, Rio de Janeiro, Paraná, Santa Catarina, Rio Grande do Sul e Minas Gerais. Destes, incluo aqui como material de análise apenas o de São Paulo, justamente porque há uma grande semelhança nos enunciados que circulam nestas capitais. A escolha se deu por dois critérios teórico-metodológicos: a hipótese de que há formas de sujeito, de identidade, que são mais desejáveis do que outras, o que confirmaria minha tese de uma hierarquia; a permanência de certos centros urbanos como produtores principais de discursos e práticas de afetividade, de sexualidade e de identidade no Brasil.

Uma pesquisa sobre os perfis do Disponível.com, nestes moldes, havia sido realizada por Zago (2009), que percorreu vinte perfis em busca de averiguar as construções de identidade "masculinas" que o site engendrava e, a partir daí, o que acabava por excluir como o seu negativo. Minha leitura dos perfis terá discussões que tangenciam, muitas vezes, as conclusões a que chegou esse autor. No entanto, o ponto axial, aqui, é esboçar um funcionamento discursivo que expulsa o par "passivo/efeminado" da ordem da verdade da homossexualidade.

Então, vejamos, nos perfis consultados: os dez mais visitados totalizam a impressionante soma de mais de dez milhões de visitas. Chamam a atenção, de imediato, algumas "características" comuns a todos: são usuários que se descrevem como ativos (apenas um deles se coloca como “versátil", ativo e passivo), que possuem pênis avantajados devidamente 
comentados e expostos e que se apresentam e exigem "discrição" e "masculinidade". A expressão que é mais comum e que subsume todos esses atributos é "macho ativo". As identidades que tangenciam esse discurso do "macho ativo", então, serão engendradas a partir de uma encenação discursiva do corpo, que aparece em texto e em imagens materializados em pênis devidamente mensurados e nos músculos que exibem um paradigma de beleza para o dispositivo sexual contemporâneo. Leiamos a seção Sobre Mim $^{1}$ do perfil dos dois primeiros colocados:

Corpo,

20cmmachoativo: SOU UM CARA MACHO DE ATITUDE... CURTO ARROMBAR RABOS COM ATOLADAS... FAÇO DESDE SEXO LEVE ATÉ HARD... CURTO MUITO PASSIVOS SUBMISSOS, OBEDIENTES... MIJADOR DE PRIMEIRA [...]. masculinidade e efeminização

Jogador-sacana-fodedor-de-machos: SOU MÁSCULO, ATIVO, DOMINADOR, SACANA E PUTÃO, MALHADO, PARRUDO COM CARA CORPO E BARRIGA DE MACHO.

Como se nota, a identidade do "macho ativo" engendra um problema para seu suposto duplo, o "passivo", que deseja ser dominado. Nessa economia erótica, a condição de sua satisfação é a manutenção de uma hierarquia rígida de papéis sexuais. No discurso sobre a homossexualidade, isso implica uma negativização dos sujeitos, que passam a encenar-se da perspectiva do Outro desses "vencedores". Dito de outro modo: se, no Disponível.com, os perfis mais acessados são os que asseveram a produção de identidades ativas e masculinas, esse "sucesso" faz inferir um fracasso correspondente: o das identidades que se marcam pelos enunciados da passividade e da efeminização.

Zago (2009, p. 210) discute essa ambiguidade, afirmando que a política de separação entre ativos e passivos corresponderia a uma troca díspar, pela qual a cisão com a masculinidade ficaria reservada apenas ao passivo, que então deveria constantemente se enunciar como "discreto", "não efeminado". Se observarmos as descrições de $20 \mathrm{~cm}$... e de Jogador..., a incidência de uma des-masculinização do outro é flagrante, pois seu discurso recorre aos enunciados da submissão e da dominação,

1 Os dados são de outubro e novembro de 2011. Mantive a grafia original e o uso de maiúsculas, o que na internet é inferido como uma espécie de "grito", com força elocucional imperativa. 
numa retomada do arquivo "bicha-bofe" sobejamente denegado pelo discurso da afirmação homossexual.

Na seção Procuro Por, essa dramática axiológica fica mais evidente. Entre o que desejam os melhores ranqueados, há um imperativo de masculinidade para os passivos:

Paugrosso10: Caras passivos e versáteis, com o corpo em forma. Sem fotos nem leio as mensagens. Não curto ativos, gordos, peludos, cds, trans nem cara que se dizem machos e usam calcinha.

Atilio Butturi Junior

Brazaguy: Procuro amizades, ficadas e se rolar algo sério com caras bem humorados, HONESTOS e fisicamente Só curto CARAS SARADOS, mas que não se resumam em apenas aparência... E MACHOS!!!! (gordinhos, foras de forma, corpo 'normal', ciumentos, desculpem, mas é gosto!).

Machodesungão: Macho, inteligente, bom papo, que curta viajar, cinema, teatro e muito sexo.

Nos três discursos, começa a operar um funcionamento paradoxal, aos moldes do que veremos em relação ao fantasma: ao mesmo tempo que se exigem parceiros "machos", são eles que deverão fazer as vezes de passivo. As marcas do discurso também enunciam corpos ideais, construindo diversas séries de exclusão, que passam por todas as modalidades de "não sarados". Para o passivo e o efeminado que se vislumbra, uma dupla exclusão: do verdadeiro e do desejável, pois a masculinidade homossexual buscada - e visitada ${ }^{2}$ - é construída a partir de performances de que não podem tomar parte; a exclusão pela normatização, já que apenas são legítimas as formas de sujeito que podem circular nesse universo monossexual do discurso.

Dessa perspectiva, o questionamento retorna ao sugerido pela arqueogenealogia: por que o passivo e o efeminado surgem como um problema? Por que precisam de atenção, de escansão, de disciplina? No caso do brasileiro, os questionamentos ainda são percorridos pelos discursos da igualdade e da diversidade: como manter, no interior das empresas plurais, as teses de ultrapassamento da hierarquia se é justamente a seu retorno sintomático a que se assiste?

2 Apenas quatro perfis são de sujeitos "passivos", entre os sessenta perfis ranqueados que utilizei. 
O ubuesco desse retorno - afinal, nunca devidamente reprimido - pode ser lido em um dos perfis, o sexto colocado no ranqueamento, com mais de um milhão de visitas: Machoativoquermacho. Nas seções Sobre Mim e Procuro Por, ele assim se categoriza:

Machoativoquermacho: Macho separado de mulher... com pegada forte...kct grande grosso com XXII cm...socador...dominador...homem com cara de macho...bom nível...cem por cento ativo [...] macho que fode outro macho na moral.

Corpo, masculinidade

Machoativoquermacho: [Procuro Por] Que tenha jeito de homem...Pode ser ativo, passivo ou versátil...caras maneiros para curtir os prazeres do sexo, sempre na encolha [...].

O discurso do usuário guarda um paradoxo: ao mesmo tempo que se enuncia respeitando o modelo da virilidade - inclusive incluindo os atrativos da insuspeita heterossexualidade ("separado de mulher") - Macho... sugere uma contradição: seu parceiro pode ser "ativo, passivo ou versátil". Como se trata dos "prazeres do sexo", ao que parece, a inclusão de outras categorias seria, no mínimo, "profícua". Ocorre, porém, que o desejo inunda o enunciado de paradoxos lógicos: ou bem Macho... é ativo (ele identifica-se como "cem por cento ativo") e procura pelo conjunto dos parceiros a quem pode dominar e em quem pode "socar", ou bem Macho... já não é mais "ativo" e então deve responder pela audácia da diversidade de seu desejo na hierarquia monossexual do Disponível.com.

Esclareço: o problema que aqui cabe discutir não é o da multiplicidade do discurso do desejo, da qual Macho... seria o representante. O que é preciso observar é a necessidade de silenciamento e exclusão da passividade e da efeminização do discurso verdadeiro dessa masculinidade homossexual. Seu aparecimento, então, ainda que denegado, responde a uma série de modificações e deslocamentos do discurso monossexual brasileiro: em sua aparição gloriosa, urdindo uma separação entre o racionalismo urbano e a tradição arcaizante; mais tarde, na assunção da identidade gay e no controle da diversidade "perversa"; nos discursos que circulam no Disponível.com, segundo a ordem de uma escrita de si privada, numa série de negativizações e hierarquias e, no limite do risível, num silenciamento ineficaz e numa reaparição repetida e fantasmática. 
Esse fantasma, do qual se falará a seguir, é ainda o modo do funcionamento dos discursos dos sujeitos homossexuais que acessam o Bate Papo UOL. Se o Disponível.com sugere, como se viu, uma série de classificações e de hierarquizações, passo a questionar se esse jogo discursivo acontece em outro gênero de site, que não demanda cadastramento ou atualização do perfil. Dessa perspectiva, o Bate Papo UOL adensaria o constante anonimato e permitiria uma maior liberdade enunciativa, da ordem da intimidade e do privado, que já estavam presentes no Disponível.com.

Atilio

Butturi Junior

\section{O bate-papo do UOL}

Interessava-me, pois, averiguar, ao menos de forma incipiente, de que modo a ambígua relação entre a masculinidade, a passividade e a efeminização percorria o jogo discursivo das salas de bate-papo, cujo papel na transformação das práticas homossexuais e da produção dos sujeitos ainda foi pouco discutido no Brasil.

Minhas observações duraram cerca de três meses (setembro, outubro e novembro de 2011), com visitas a salas de bate-papo do UOL de diversas regiões do Brasil e de diferentes temáticas - as categorias principais foram Assinantes, Cidades e Regiões e Outros Temas. O UOL foi escolhido porque mantém as salas de bate-papo com a maior quantidade de acessos no Brasil, que somam mais de 70 mil pessoas simultaneamente conectadas. Ademais, mantém uma rede de assinantes que passa de 2 milhões de pessoas (UOL, 2011). Para o Bate Papo, essas assinaturas são importantes, pois dão acesso irrestrito às salas, enquanto os usuários comuns têm acesso restrito segundo uma lotação máxima de trinta pessoas.

Durante as observações, o primeiro problema que se revelou foi a diversidade das salas. Assim, a escolha foi menos regional e partiuse de uma delimitação: as salas de Sexo Gay nacionais. Outro problema dizia respeito ao modo de abordagem dos sujeitos. Como não se tratava de uma pesquisa etnográfica, mas de uma análise discursiva, a saída metodológica foi a produção de uma pequena entrevista estruturada, composta de questões que versavam sobre os discursos que já tinham sido observados: a insistência em designações de si (os nicknames que cada usuário utiliza) marcadas pela presença de indicadores dos papéis sexuais e da faixa etária; a permanente publicização de enunciados explicitamente "hierárquicos", nos quais os sujeitos esclareciam os objetivos de sua presença na sala. 
Esses discursos guardam uma relação importante com a nomeação, que abordo antes de passar às entrevistas. Nas salas, cada usuário escolhe um "apelido" (nickname) para se comunicar com os demais. No caso das salas voltadas para o "tema" sexo, é comum que esses nicknames façam menção a partes do corpo ou papéis sexuais. Assim como acontecia no Disponível.com, a construção de uma identidade gay no Bate Papo UOL Sexo Gay parte de um discurso marcadamente hierárquico, em que ativos e passivos encenam formas de sujeito incomensuráveis. Para deslindar essa produção de identidades via nomeação, recorro às nomeações encontradas em dez dessas salas, entre 15 de janeiro e 3 de fevereiro de 2012. Como o UOL oferece a ferramenta "Espiar", não é necessário que se entre na sala para saber quais são os usuários presentes em cada momento.

Corpo, masculinidade e efeminização

Numericamente, o total de usuários on-line somou 352 pessoas. Nesse universo, aventei a existência de duas categorias recorrentes: a nomeação por papel sexual, que incluía também a menção direta ao corpo ("Pau", "Cu"); e a nomeação por faixa etária. A primeira categoria foi utilizada por 96 usuários, divididos entre ativos e passivos e suas corporalidades (as grafias são as mesmas dos usuários): \#BUNDINHA na CAM, 20cmTorto Gozar, rolão 21x5, NEGAO DOTADO, machoputinha, japinhaviadinho, ticudoarregaçacu e bundabranca. A listagem, porém, não é infinita. Durante os meses de observação, pode-se aduzir uma espécie de gramática, bastante rígida em sua normatização. Assim é que, em sala de Bate Papo de Cidades, aparecem recorrentemente os mesmos nicknames, segundo os mesmos regramentos, quais sejam: formas de subjetivação na internet construídas a partir da atividade são marcadas pela enunciação explícita do "pênis" (e seus derivados mais "obscenos", "pau", "kct" etc.) e de seu tamanho e por verbos que denotam "dominação", como "meter", "arregaçar"; enquanto formas de subjetivação produzidas a partir da passividade marcam-se pela recorrente menção à "bunda" (e seus derivados, "cu”, "rabo" etc.) e por verbos relativos ao intercurso anal ("rebolar", "piscar").

Outra categoria importante é a etária, que aparece em 102 dos 352 nomes. Os sujeitos se identificam de acordo com sua juventude, que muitas vezes está relacionada ao papel sexual passivo - novamente, conforme os enunciados de hierarquização que já foram citados neste texto, a passividade permanece envolta numa série de preocupações. Quanto à idade, os nicknames recorrentes são aqueles que contêm a 
ordem numérica explícita ("17a", por exemplo) ou que produzem um efeito de "juventude": "leke", "milico", "boy", “estudante”, “novin" (leia-se "novinho").

Nas duas classificações, é importante a função dos graus aumentativo e diminutivo, economicamente complementares nesse discurso. Há uma recorrente produção de subjetividades "mais masculinas" e "mais afeminadas" que recorre, respectivamente, ao aumentativo e ao diminutivo. Enquanto os primeiros engendram uma valorização da virilidade pelo efeito da gradação positiva - em "marko-picaocam" ou "atiAtilio vao", - os outros surgem a partir de dois efeitos do diminutivo, muitas Butturi Junior vezes concomitantes: de gradação negativa/submissão e de juventude. Nesse universo, estão "Noivinho pass fone", "virgenzinho 15 anos" e seus avatares.

A taxionomia, é preciso esclarecer, não obedece à referencialidade. Trata-se de uma encenação discursiva, de um jogo em que as identidades são construídas a partir do código moral e que pretende simular uma produção de sujeitos e de corporalidades a partir da regra heteronormativa-monossexual - como gostaria Butler (2001) -, que demanda a adesão ao regramento, sob pena de sanções relativas ao circuito afetivo-sexual. Dessa perspectiva, Braz (2007) aponta que, em São Paulo, a primeira década do século XXI recorre a uma distribuição entre as identidades "masculinas" e as demais, as tornadas "abjetas" (BUTLER, 2001). Segundo o autor, a rejeição, na economia da sociabilidade, recai sobre os sujeitos atravessados pelo negativo da configuração: pobres, "bichinhas pocpoc", "afeminados".

Além disso, é um mesmo jogo que instaura uma exigência de verdadeiro masculino/ativo no usuário do Disponível.com, Machoativoquermacho e nos nicknames do UOL: o do interdito da passividade e da efeminização e o da permanência fantasmática da hierarquia. As escansões do discurso são claras: há uma sociabilidade que permite a "união" entre a diversidade homossexual. Essa ambiguidade diz respeito a uma fundamental separação entre a moralidade de uma forma de subjetivação modernizante e uma repetição-retorno de uma pessoalização arcaica e tradicional, conforme as descrições de Da Matta (1997). Silenciadas e denegadas, elas reaparecem, implacáveis, como espectros do discurso monossexual ${ }^{3}$.

3 "Monossexual" é uma categoria discursiva aventada por Michel Foucault para se referir à relação 
Mais profundamente, todavia, destaco o duplo funcionamento desse discurso. Se, por um lado, os entrevistados assumem um enunciado da diversidade ("entre os gays" ou "na sociedade em geral", ou seja, fora do "mundo gay"), essa assunção é apenas pública, social, de um sujeito modernizante. Diametralmente oposta, então, está a esfera do pessoal, marcada pela adversatividade de uma individuação: "particularmente" ou "pessoalmente" os discursos são atravessados pela hierarquização e exigem a escansão. No caso da monossexualidade, então, teríamos uma ambiguidade constitutiva: uma identidade disciplinarizada, contemporânea, viril, urbana e culta. Uma identidade fora da norma, expulsa e silenciada no interior desse discurso da verdade do sexo e do sujeito.

Corpo, masculinidade e efeminização

\section{Considerações finais}

Certamente, os recortes do Disponível.com e do Bate Papo UOL não são suficientes para a criação de uma teoria geral das práticas on-line nem para delinear uma configuração única e totalizadora para a objetificação e a subjetivação das homossexualidades. Nem era esse o intuito, mas apenas o de fazer supor uma presença incômoda na liberdade, uma manifestação mais astuta do poder, que se desloca e continua a circular, criando corpos e sujeitos e os repartindo, fantasmaticamente.

No caso da homossexualidade masculina no Brasil do século XXI, nota-se a permanência de uma economia dos enunciados que obedece à lógica de um fantasma, cujo duplo funcionamento discursivo revelava a manutenção de um discurso público da igualdade e da diversidade, contraposto a um discurso hierárquico e repetitivo, da ordem do privado e do fantasmático. É esse espectro que encerra o artigo. Encerra porque é com ele, afinal, que se pretende interpretar as escansões e os retornos realizados pelo discurso sobre/das homossexualidades em relação aos enunciados e práticas de "passividade" e "efeminização". Encerra, ainda, porque circunscreve a homossexualidade on-line a um discurso menos revolucionário e, de alguma forma, mais micropolítico. Dito de outro modo: repensar a volta das homossexualidades abjetas como fantasma da monossexualidade contemporânea exige que se entenda a série de reescritas e deslocamentos produzida pelo próprio

entre homens não estigmatizada e simétrica. Essa ordem, chamada pelo autor de "monossexual", permitiria o abandono de relações desiguais ou estigmatizadas (FOUCAULT, 2010a, p. 124). 
discurso homossexual brasileiro, quando este se pretendia "libertário" ou "subversivo". Exige uma tomada de posição que investigue as "baixas origens" dos esforços de produção de sujeitos mais livres e, no mesmo movimento, que se interrogue sobre a permanência e o retorno dos discursos, sempre disciplinarizadores, amiúde ubuescos.

Dessa perspectiva, no campo da sexualidade e da produção, a alternativa do texto foi espectralmente reacionária, descrevendo um itinerário ainda problemático de identificações e separações que constituem - ainda - a discussão sobre/das homossexualidades brasileiras.

Atilio De um reacionarismo, porém, feliz.

\section{Referências}

BRAZ, C. A. de. Macho versus Macho: um olhar antropológico sobre práticas homoeróticas entre homens de São Paulo. Cadernos Pagu, Campinas, n. 28, p. 175-206, jan./jun. 2007. Disponível em: <http:// www.scielo.br/scielo.php?pid=S0104=83332007000100009-\&scriptsci_arttext>. Acesso em: 24 set. 2009.

BUTLER, J. Corpos que pesam: sobre os limites discursivos do sexo. Trad. de Tomaz Tadeu da Silva. In: LOURO, Guacira Lopes (Org.). 0 corpo educado. Belo Horizonte: Autêntica, 2001. p. 151-172.

DA MATTA, R. A casa e a rua: espaço, cidadania, mulher e morte no Brasil. 5. ed. Rio de Janeiro: Rocco, 1997.

DELEUZE, G. Foucault. Trad. de Claudia Sant'Anna Martins. São Paulo: Brasiliense, 2005.

DISPONÍVEL.COM. 2011. Disponível em: <http://disponivel.uol.com. br/web/>. Acesso em: 22 out. 2011.

EWALD, F. Foucault, a norma e o direito. 2. ed. Lisboa: Vega, 2000.

FOUCAULT, M. O triunfo social do prazer sexual: uma conversação com Michel Foucault. In: Ditos e escritos V: ética, sexualidade 
e política. Trad. de Elisa Monteiro e Inês Autran Dourado Barbosa. 2. ed. Rio de Janeiro: Forense Universitária, 2010a. p.119-125.

A ética do cuidado de si como prática da liberdade. In: FOUCAULT, M. Ditos e escritos V: ética, sexualidade e política. Trad. de Elisa Monteiro e Inês Autran Dourado Barbosa. 2. ed. Rio de Janeiro: Forense Universitária, 2010b. p. 264-287.

História da sexualidade I: a vontade de saber. Trad. de Maria Thereza Albuquerque e J. A. Guilhon Albuquerque. 19. ed. Rio de Janeiro: Graal, 2009a.

História da sexualidade II: o uso dos prazeres. Trad. de Corpo, masculinidade e efeminização Maria Thereza da Costa Albuquerque. 13. ed. Rio de Janeiro: Graal, $2009 \mathrm{~b}$.

Genealogia e poder. In: Microfísica do poder. Trad. de Roberto Machado. 11. ed. Rio de Janeiro: Graal, 1993a. p.167-177. Não ao sexo rei. In: Microfísica do poder. Trad. Roberto Machado. 11. ed. Rio de Janeiro: Graal, 1993b. p. 229-242. Sobre a história da sexualidade. In: Microfísica do poder. Trad. de Roberto Machado. 11. ed. Rio de Janeiro: Graal, 1993c. p. 243-276.

Vigiar e punir: nascimento da prisão. 2. ed. Petrópolis: Vozes, 1993d.

HEILBORN, M. L. Homossexualidade feminina em camadas médias no Rio de Janeiro sob a ótica das gerações. In: VELHO, G.; DUARTE, L. F. D. (Org.). Gerações, família, sexualidade. Rio de Janeiro: 7Letras, 2009. p. 77-88.

LÉVY, P. Cibercultura. São Paulo: Edições 34, 1999.

MAINGUENEAU, D. Análise de textos de comunicação. 2. ed. São Paulo: Cortez, 2002. 
PERLONGHER, N. O negócio do michê: prostituição viril em São Paulo. São Paulo: Brasiliense, 1987.

UOL. Sobre o UOL. 2011. Disponível em: <http://sobreuol.noticias. uol.com.br>. Acesso em: 23 maio 2011.

Bate-papo UOL. 2012. Disponível em: <http://batepapo.uol. com.br> Acesso em: 2 jan. 2012.

Atilio WEINMANN, A. de O. Dispositivo: um solo para a subjetivação. Psicologia \& Sociedade, Porto Alegre, v. 18, n. 3, p. 16-22, set./dez. 2006. Disponível em: <http://www6.ufrgs.br/seerpsicsoc/ojs/viewarticle. php?id=42\&layout=html>. Acesso em 22 set. 2010.

ZAGO, L. F. Masculinidades disponíveis.com: sobre como dizer-se homem gay na internet. 2009. 227 f. Dissertação (Mestrado em Educação)-Universidade Federal do Rio Grande do Sul, Porto Alegre, 2009. 